This item was submitted to Loughborough's Research Repository by the author.

Items in Figshare are protected by copyright, with all rights reserved, unless otherwise indicated.

\title{
Agent-based modelling and simulation through video observation analysis
}

PLEASE CITE THE PUBLISHED VERSION

https://doi.org/10.1142/9789814417747_0066

\section{PUBLISHER}

(C) World Science Publishing

VERSION

AM (Accepted Manuscript)

\section{PUBLISHER STATEMENT}

This work is made available according to the conditions of the Creative Commons Attribution-NonCommercialNoDerivatives 4.0 International (CC BY-NC-ND 4.0) licence. Full details of this licence are available at: https://creativecommons.org/licenses/by-nc-nd/4.0/

\section{LICENCE}

CC BY-NC-ND 4.0

\section{REPOSITORY RECORD}

Mohamaddan, Shahrol, and Keith Case. 2019. "Agent-based Modelling and Simulation Through Video Observation Analysis". figshare. https://hdl.handle.net/2134/34397. 
In C. Kahraman, E. E. Kerre and F. T. Bozbura (Eds.) World Scientific Proceedings Series on Computer Engineering and Information Science, Volume 7, 'Uncertainty Modeling in Knowledge Engineering and Decision Making', the Proceedings of the Tenth International FLINS Conference (pp. 412-417). Istanbul, Turkey: World Science Publishing Co. Singapore, 26-29

August 2012.

\title{
AGENT-BASED MODELLING AND SIMULATION THROUGH VIDEO OBSERVATION ANALYSIS
}

\author{
SHAHROL MOHAMADDAN ${ }^{\dagger}$, KEITH CASE \\ Mechanical and Manufacturing Engineering, Loughborough University \\ Loughborough, Leicester, LE11 3TU, UK
}

\begin{abstract}
The understanding of human behaviour in the real world is important aspect of attempts to develop effective tools that simulate humans in areas such as ergonomics, manufacturing, transportation, psychology and architecture. In this research, video observation studies and analysis is applied to understand the individual human behaviour in crowded spaces. Individual human behaviour is modelled and simulated using 'agents' with differing characteristics and abilities in a virtual environment. The focus is on developing a simulation method that supports an 'inclusive' sustainable environment which allows full participation of the elderly and disabled people in society.
\end{abstract}

\section{Introduction}

Fire hazards, accidents, earthquakes and other emergencies are examples of phenomena that always threaten human live. Such phenomena become major issues when they occur in crowded spaces such as stadia, spiritual places, train stations and other public facilities. Considerable research has been conducted to understand the phenomena and increase crowd safety through methods such as human crowd modelling. Most of this research focuses on human movement and behaviour during the evacuation process, especially in emergency situations. In the evacuation process, the humans in the crowd is approached from a macroscopic level where the movement and behaviour is considered to be similar to the movement of fluid [1], gases [2] and the movement of a school of fish or a flock of birds responding to external stimuli.

Macroscopic approaches have limitations in representing the human in crowd as individuals with different characteristics and abilities. The research work in [1-3] are examples of the application of the macroscopic approach. However, the current research is focused on a microscopic approach where individual human behaviours and interactions within the crowd are considered. For example, different types of activity can be found within the crowd at train station such as queuing for ticket machines, social interaction, moving with luggage and shopping. In order to model and simulate these kinds of behaviour within the microscopic approach, agent-based modelling is applied. 
The agent-based modelling is a 'bottom up' computational model that simulates individual humans as 'agents' within the virtual environment. Work in [4] is an example of agent-based modelling. In the current research, heterogeneous characteristics of humans, particularly for older and disabled people, is developed as part of major research project known as AUNT-SUE (Accessibility and User Needs in Transportation for Sustainable Urban Environments) [5].

\section{Conceptual Behaviour}

In order to acquire relevant information about individual human behaviour through video observation, the conceptual behaviour is developed as a foundation for what is going to be observed and analysed. In this way, better insight into human behaviour can be achieved whilst avoiding any confusion during the observation process due to the large volume of movement and behaviour within the recorded video. Conceptual behaviour is considered as a set of behaviours that are acquired from the major human movements of free movement, opposite direction movement and same direction movement.

Free movement is considered as a basic human movement from one point of interest to another point of interest. In free movement, the human is considered to have enough space to move without facing any obstacle or constraint during the movement. There are two types of behaviours that can occur during free movement; Moving Through Behaviour and Move-Stop-Move behaviour. Moving Through is behaviour where the human just move through the observation area without any specific concern. The only difference that can be observed between humans is the speed of movement. Move-Stop-Move is the behaviour where humans have to stop a few seconds or a few minutes to perform some other related task during the movement such as buying a ticket, using a mobile phone, waiting for someone or looking for information.

Opposite direction refers to the condition where a human meets another human travelling in the opposite direction, for example when moving along a pathway. Upon meeting each other during the movement there are two possible behaviours that can occur; Avoiding Behaviour and the Passing Through behaviour. Avoiding refers to the behaviour where the human gives way to other people or performs an avoidance route. On the other hand, Passing Through refers to the behaviour where humans do not consider others or their surroundings during the movement. The major concern is to reach the targeted area within the planned route. Same direction movement consists of Queuing

Behaviour and Competitive Behaviour. The Queuing and Competitive Behaviours can easily be observed when humans enter or exit a door. Queuing Behaviour is the manifestation of self-organization where individual humans create a line to enter or exit the door. On the other hand, in Competitive Behaviour humans have less consideration for each other and each individual tries to enter or exit the door as quickly as possible. 


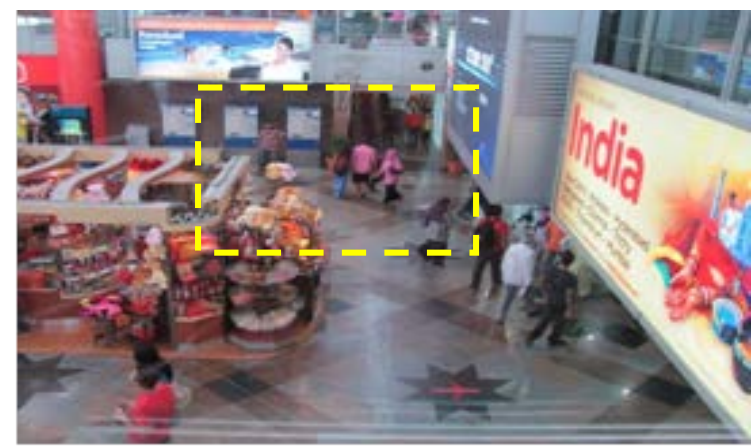

Figure 1. The observation area

\section{Observational Studies and Analysis}

The observation studies were conducted to understand and analyse the individual human movement and behaviour in crowded spaces. The observation studies were conducted at one of the largest transportation hubs in Kuala Lumpur, Malaysia. For this research, the observation studies are focusing on the exit door as shown highlighted in yellow in Figure 1. The selected exit door is a crowded interchange location that shows multi-directional movement with humans moving to the airport train and other public transportation areas for buses and taxis. In addition, there also a ticket machine, a stall and a shop located in the exit door area.

The observation studies were conducted since the method supplies more information on 'real' movement and behaviour of individual humans when compared with questionnaires and laboratory experiments. In laboratory experiments, the incentive and early instruction given to the participant can influence their psychological condition, and there are many factors that affect the real world traffic so that for example different crowd is observed at train station and shopping malls. Both conditions cannot be observed under laboratory conditions. In this research, a video camera is used to record the 'real' human movement and behaviour. The video camera is situated at the opposite side of the exit door and provides an aerial view of the human activities.

Table 1. Number of subjects by behavior

\begin{tabular}{|c|c|c|c|c|c|c|}
\hline No. & Behaviour & $\begin{array}{l}\text { No. of } \\
\text { Older } \\
\text { People }\end{array}$ & $\begin{array}{c}\text { No. of } \\
\text { Disabled }\end{array}$ & $\begin{array}{l}\text { No. of } \\
\text { Adult }\end{array}$ & $\begin{array}{l}\text { No. of } \\
\text { Others }\end{array}$ & Total \\
\hline & Free Movement & & & & & \\
\hline 1. & Moving Through (MT) & 97 & 6 & 3,444 & 63 & 3,610 \\
\hline \multirow[t]{2}{*}{2.} & Move-Stop-Move (MSM) & 17 & 0 & 260 & 4 & 281 \\
\hline & Opposite Direction Movem & & & & & \\
\hline 3. & Avoiding (AB) & 1 & 0 & 109 & 0 & 110 \\
\hline 4. & Passing Through (PT) & 6 & 0 & 56 & 2 & 64 \\
\hline
\end{tabular}


Same Direction Movement

\begin{tabular}{|c|c|c|c|c|c|c|}
\hline 5. & Queuing (QB) & 0 & 0 & 82 & 0 & 82 \\
\hline 6. & Competitive (CB) & 2 & 0 & 23 & 0 & 25 \\
\hline & Total & 123 & 6 & 3,974 & 69 & 4,172 \\
\hline
\end{tabular}

The observation studies were conducted during the weekend and weekday, one hour each starting from $7.30 \mathrm{am}$ to $8.30 \mathrm{am}$ in the morning. In total 4,172 humans were observed (1,152 during the weekend period and 3,020 during the weekday period). The start and end times of the observations were determined as the peak-time on a weekday when people start using the transportation services to travel to the workplace and leisure time during the weekend. There are four different types of subject that form the focus for the studies, the elderly, disabled, adult and others (children or workers that moving around with trolley and cleaning devices).

The number of subjects by behaviours is shown in Table 1. Based on the two hours video observation analysis, 95.3 per cent of the subjects or 3,974 people are adult. Disabled people are the group of subjects that are rarely observed with only 6 people or 0.1 per cent in the two hours recording. In general, most of the human behavior was free movement especially during the weekend when there are small numbers of humans and bigger spaces to move around.

\section{Behavioural Model}

The observational studies and analysis shows that there are several factors affecting individual human behaviour within the crowded spaces. Based on the limited two hours observation, there are four factors that are considered to affect human behavior; personal objectives, field of view, speed of movement and personal space. The four factors are the basis on which the behavioural model or set of rules for the simulation were constructed.

\subsection{Personal Objective}

Personal objective refers to the goal that human has during the movement. The observation studies and analysis shows that humans have different types of personal objectives and it can be observed based on the physical appearance within the recorded video, that although there is no direct communication between individuals in the crowd. For example, there is the human moving with luggage or backpack, looking for information, buying a ticket at the ticket machine and other activities. The personal objective is the main reason that determines human decision making and behaviour during movement in crowded spaces. 


\subsection{Field of View}

Field of view (FOV) refers to the extent of the observable range seen by a human at any given moment, where in the human FOV is around 120 to 180 degrees [6]. FOV is important since humans develop their perception of the environment during the movement primarily from visual data. The importance of FOV is observed during the Move-Stop-Move Behaviour as shown where human movement becomes slower when looking for information during the journey. There is the possibility of performing the Move-Stop-Move Behaviour in order to acquire persistent information so that a personal objective is achieved. In general, older and disabled people having a smaller FOV compared to young and able-bodied which is a contributory cause of the difficulty older and disabled people have when moving within the crowded spaces.

\subsection{Speed of Movement}

Speed of movement refers to the walking speed of humans, classified into slow, average, fast and extra fast [7]. Humans are observed to have slow or average speed of movement when performing the Moving Through and Move-StopMove Behaviours. However, when performing the Competitive and Passing Through Behaviour humans are observed to have faster (fast or extra fast) speed of movement.

\subsection{Personal Space}

Personal space refers to the invisible surrounding or territory around human beings. Personal space is considered as a social condition that affects communication or contact between humans. The personal space is divided into four categories known as the Intimate, Personal, Social Consultative and Public Zones which are based on the distance between humans within the public spaces. In general, older and disabled people have a larger personal space compared to the young and able-bodied. The workers with trolleys, families with children in strollers, humans with luggage and humans in group are observed to need a greater personal space.

\section{Simulation}

In this paper, the simulation conducted is focused on two types of movement which are the opposite direction movement and same direction movement. The simulation is conducted using the DarkBasic Professional software. Individual humans are represented by an agent in circular shape with different colours representing adults, older and disabled people which have differing characteristics and abilities. Each agent is programmed to move to the selected objective with different FOV, speed of movement and personal space similar to the real world movement and behaviour. Work in [7] shows an example of simulation based on London Paddington station. 


\section{Conclusion}

This paper presents the development of agent-based modelling and simulation system through video observational studies and analysis based on a conceptual behaviour model. Video observational studies and analysis provide a better input towards understanding human behaviour in real life situations. The simulation conducted offers valuable understanding of human behaviour and environments which is potentially valuable to the planners and designers. However, the observational studies conducted are limited and there is a need to increase the observational time in order to get better insight of human behaviour. A full-scale case study for the research is also need to be conducted in order to test the parameters.

\section{References}

1. P. Thompson and E. Marchant, Safety Science, 18, 277 (1995).

2. D. Helbing, M. Isobe, T. Nagatani and K. Takimoto, Physics Review E, 67, 067101 (2003).

3. L. Yang, D. Zhao, J. Li and T. Fang, Building and Environment, 40(3), 411 (2005).

4. F. Cherif and R. Chighoub, Journal of Computing, 2(4), 48 (2010).

5. AUNT-SUE, http://www.aunt-sue.info/, (2011).

6. S. Sukhatme, http://www.artinarch.com/vp05.html/, (2011).

7. K. Case, M. Freebody, S. Mohamaddan and S.T. Syed Shazali, in Proceedings of the $9^{\text {th }}$ International Conference on Manufacturing Research, edited by D.K. Harrison, B.M. Wood and D. Evans (2011), p. 31 